\title{
REMOVAL OF ERIOCHROME BLACK T DYE FROM AQUEOUS SOLUTION BY NICKEL/ALUMINIUM LAYERED DOUBLE HYDROXIDE
}

\author{
NURDIYANA ROSLAN ${ }^{1}$, MAZIDAH MAMAT ${ }^{1,2^{*}}$ AND KU HALIM KU BULAT $^{1}$ \\ ${ }^{1}$ School of Fundamental Science, Universiti Malaysia Terengganu, 21030 Kuala Terengganu, \\ Malaysia \\ ${ }^{2}$ Advanced Nano Materials Group, School of Fundamental Science, Universiti Malaysia \\ Terengganu, 21030 Kuala Terengganu, Malaysia
}

*Corresponding author: mazidahmamat@umt.edu.my

\begin{abstract}
Batik industry is well known in the East Coast of Malaysia, particularly in Terengganu and Kelantan. This industry consumes a lot of water for the batik making process which contributes to high discharge of wastewater containing excess dye pollutants. Hence, in this study, an anionic clay of nickel/aluminium-layered double hydroxide (NiAL) was investigated as a potential adsorbent for the removal of anionic dye of Eriochrome Black T (EBT). The NiAL was synthesized via self-assembly method and characterization of NiAL was carried out using powder X-ray diffraction (PXRD) and Fourier transform infrared spectrophotometer (FTIR). The composition and morphology of NiAL was further analyzed using carbon, hydrogen, nitrogen, sulphur elemental analyzer (CHNS), thermogravimetric analyzer (TGA) and scanning electron microscope (SEM). The potential of NiAL as an adsorbent for the removal of EBT in aqueous solution was tested at different dosages of NiAL. The adsorption ability was analyzed by using two common adsorption isotherms, which were Langmuir and Freundlich models. The adsorption of EBT onto NiAL was governed by Freundlich isotherm model indicating that the adsorption occurs in heterogeneous system.
\end{abstract}

Keywords: Adsorption, anionic dye, Freundlich isotherm, layered double hydroxide

\section{Introduction}

One of the fastest thriving industries that majorly contributes to the economic growth in Malaysia is the textile industry. But, this industry has elevated water usage which has caused an increase in the amount of wastewater with extravagant pollutants. Pigments and dyes are commonly used in paper, leather and textile dyeing, pharmaceutical, printing, and cosmetics industries. About 10,000 different dyes weighing approximately 0.7 million tonnes are produced yearly for a vast number of industrial processes (Dave et al., 2011). During textile fibre dyeing and finishing process, the main water pollutant released is dyes (Pang \& Abdullah, 2013). Textile effluents have different types of dyes, surfactants, ionic impurities, and bleaching agents with different complex composition. Considerable percentage of dyes is eluded into the effluent during dyeing process due to their high water solubility. A mass volume of these dyes have been recognized as harmful or even carcinogenic (Dave et al., 2011). The abundance of dyes in water results in harm to the surrounding, mainly aquatic life, as it causes disruption in the re-oxygenation capacity and slows down photosynthetic activity because it obstructs sunlight, which causes anaerobic condition that retards the aquatic plants' growth. Contamination could exist in the ground and on the surface of water which causes the water to be ill-suited for other use because it may result in mutagenic effects (Luna et al., 2013).

Techniques such as adsorption, coagulation, chemical precipitation, and solvent extraction have been used as dye 
remover from solutions that are aqueous. Due to economic limitation, the development of clean and cost efficient processes is preferred, such as solvent extraction, electrolysis, ion exchange, and reverse osmosis. But these processes have certain weaknesses, such as partial removal, high operational cost and high energy requirement. Hence, it has been proven that adsorption is the most effective method.

There have been numerous studies investigating how this issue can be overcome. One of the solutions is using anionic clays known as layered double hydroxide (LDH), and also commonly known as hydrotalcite-like compound, which has managed to lure significant attention from the industries and academia (Goh et al., 2008). There are studies highlighting $\mathrm{LDH}$ and its derivatives as low budget adsorbents, which is an optimistic remediation for dyes. $\mathrm{LDH}$ is seen as budding adsorbent for wastewater treatment in the future (Zubair et al., 2017). LDH contains fairly weak interlayer bonding that permits it to showcase formidable potential to trap organic and inorganic anions (Goh et al., 2008). It can be synthesized via conventional method, by using several processes, such as precipitation/deposition reactions, anion exchange of a precursor LDH, hydrothermal synthesis, electrochemical methods, structural reconstruction, and direct synthesis via co- precipitation method (Muriithi et al., 2017). $\mathrm{LDH}$ is relatively simple to synthesize and is also economical although some of it exists as naturally occurring minerals (Goh et al., 2008). There has been a growing interest in using LDH to treat environmental contaminants ever since environmental pollution became a significant issue. Recently, increasing studies have been redirected into assessing the ability of $\mathrm{LDH}$ to separate inorganic contaminants (Goh et al., 2008). LDH has also received attention due to its amazing ionic exchange capacities. LDH could be used as a productive adsorbent for the removal of a variety of anions from solutions because it has switchable anions in the interlayer (Yanming et al., 2013). There was a study conducted by Alexandrica et al. (2015) on using $\mathrm{LDH}$ as adsorbents for anionic dye removal from aqueous solutions.

In this study, layered double hydroxide of nickel/aluminium (NiAL) was investigated as a potential adsorbent for the removal of Eriochrome Black T (EBT) dye from aqueous solution. EBT, or also called Solochrome Black $\mathrm{T}, \mathrm{C}_{20} \mathrm{H}_{12} \mathrm{~N}_{3} \mathrm{O}_{7} \mathrm{SNa}$, is a type of synthetic azo dye and is also an anionic dye commonly used in the textile industry as a type of colouring and as a complexometric indicator to determine water hardness. The schematic diagram of EBT is as shown in the Figure 1.

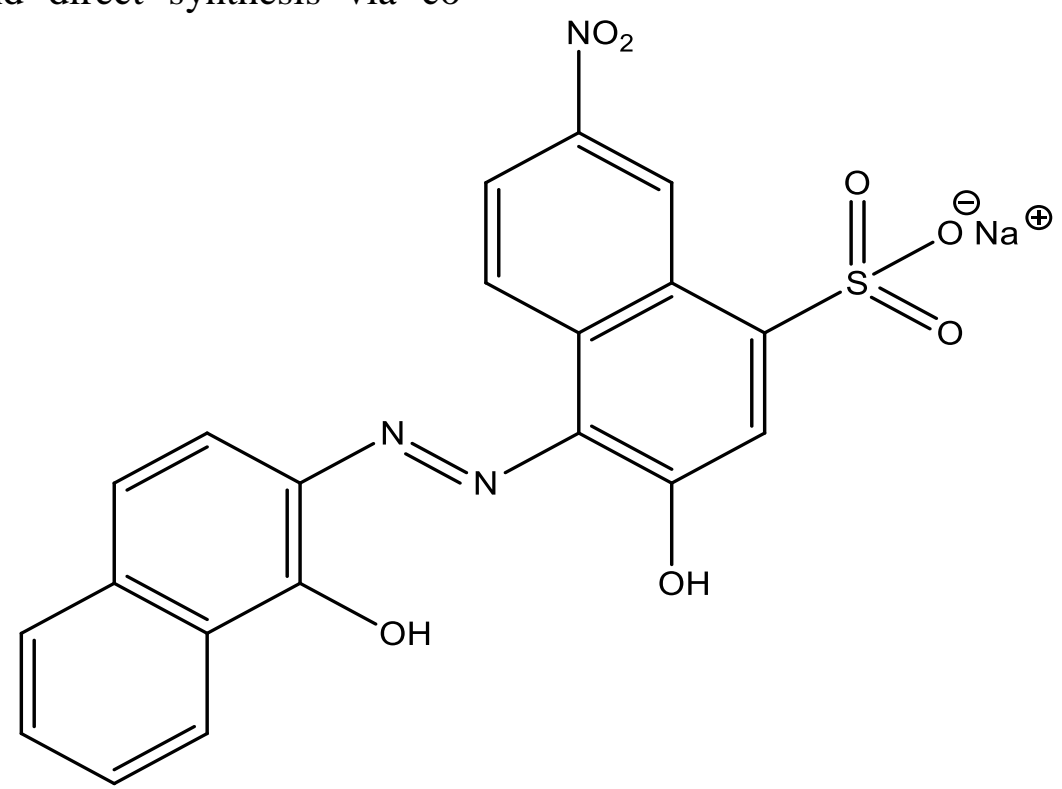

Figure 1. Structural formula of Eriochrome Black T 


\section{Materials and Methods}

The chemicals were used as received without any further purification. They were nickel (II) nitrate hexahydrate $\left(\mathrm{Ni}\left(\mathrm{NO}_{3}\right)_{2} .6 \mathrm{H}_{2} \mathrm{O}\right)$, aluminium nitrate nonahydrate $\left(\mathrm{Al}\left(\mathrm{NO}_{3}\right)_{3} \cdot 9 \mathrm{H}_{2} \mathrm{O}\right)$, sodium hydroxide $(\mathrm{NaOH})$, and Eriochrome Black $\mathrm{T}\left(\mathrm{C}_{20} \mathrm{H}_{12} \mathrm{~N}_{3} \mathrm{O}_{7} \mathrm{SNa}\right)$.

The self-assembly method was adopted to synthesize NiAL with the Ni:Al molar ratio of 2. The $\mathrm{pH}$ of the solution was adjusted to 6 by dropwise addition of $2 \mathrm{M} \mathrm{NaOH}$ into the mother liquor under nitrogen atmosphere. The solution was then aged for 18 hours in an oil bath at $70^{\circ} \mathrm{C}$ and the slurry obtained was washed with distilled water, before being filtered, dried in an oven at $70^{\circ} \mathrm{C}$ and ground into fine powder. The physicochemical properties of the synthesized NiAL was investigated by using several instruments including Powder X-Ray Diffractometer (PXRD, model Rigaku Miniflex II), Fourier Transform Infra-Red (FTIR) spectrophotometer (Perkin Elmer Precisely, Spectrum 100), Thermogravimetric Analyser (TGA, model TGA/SDTA 851), Carbon, Hydrogen, Nitrogen, Sulphur Elemental Analyser (CHNS, model FLASH EA 1112
Series), and Scanning Electron Microscope (SEM, model JSM6360LA).

The obtained NiAL was then subjected to adsorption study conducted using different NiAL dosages in a range of $0.05-0.5 \mathrm{~g}$. The $\mathrm{NiAl}$ was put in contact with $40 \mathrm{ppm}$ of $100 \mathrm{~mL}$ EBT dye solution for 60 minutes. The remaining dye concentration was determined at $\lambda=209 \mathrm{~nm}$ using UV-Vis spectrophotometer (Shidmadzu UV-1800). The data was then fitted into two adsorption isotherms namely Langmuir and Freundlich models.

\section{Results and Discussion Characterization of NiAL}

The NiAL synthesized had typical XRD pattern (Figure 2) for LDH with the basal spacing, $\mathrm{d}_{003}$, of $0.9 \mathrm{~nm}$ but with poor crystallinity as reported by previous study (Mamat et al., 2014). The obtained basal spacing value indicated the presence of nitrate anions as the interlayer ions (Miyata, 1983). The basal spacing represented the single layer thickness of NiAL together with the size of the nitrate anion. It could also be seen that the basal spacing for (003) reflection plane $\left(\mathrm{d}_{003}\right)$ was twice the $(006)$ plane $\left(d_{006}\right)$ which indicated that the product synthesized consisted of layered structure.

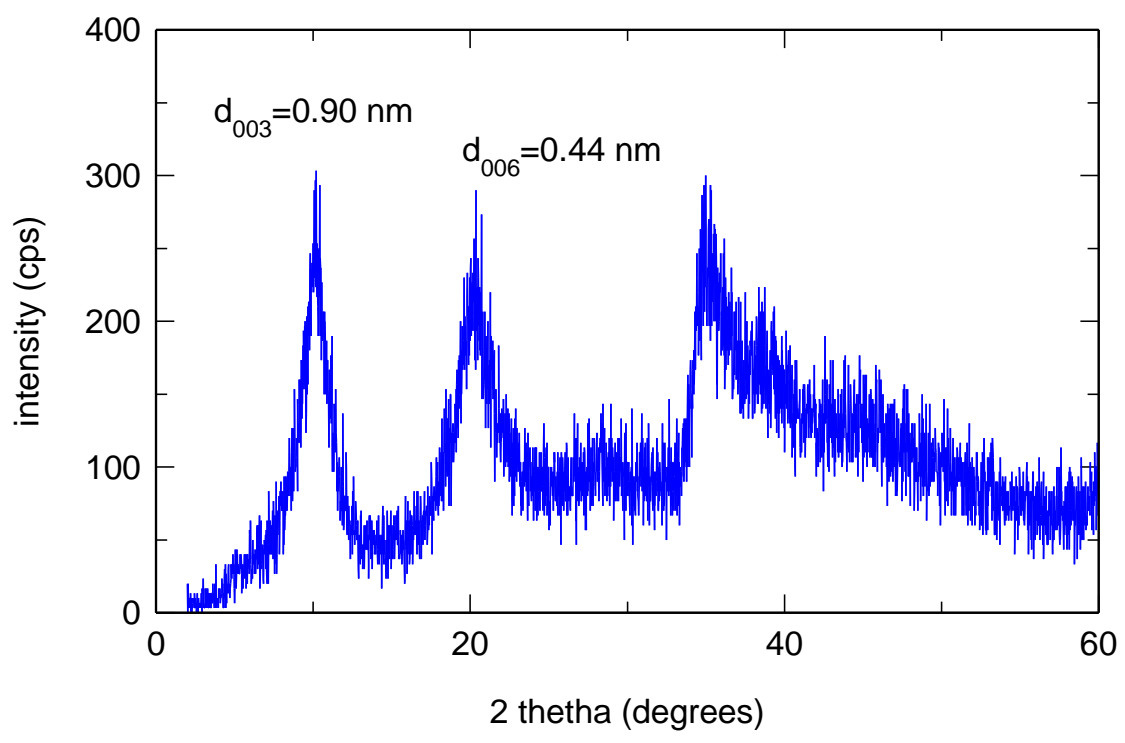

Figure 2: PXRD pattern of NiAL

The functional group information mainly the hydroxyl, metal-oxygen and the interlayer anion can be observed using FTIR analysis. The FTIR spectrum of the NiAL (Figure 3) was 
quite similar to the one obtained by Alexandrica et al. (2015). The presence of $\mathrm{OH}$ stretching of the hydroxyl group within the NiAL layers and the water molecules in the interlayer can be marked with a broad intense band centred at around $3400 \mathrm{~cm}^{-1}$. A peak observed at $1627 \mathrm{~cm}^{-1}$ can be ascribed to the $\mathrm{HOH}$ deformation $\left(\delta_{\mathrm{H}-\mathrm{O}-\mathrm{H}}\right)$, due the existence of water molecules located in the interlayer region (Feirrera et al., 2006) of NiAL. The presence of nitrate anions in the NiAL was shown by a strong and sharp peak at $1384 \mathrm{~cm}^{-1}$ as it signified the $\mathrm{NO}_{3}{ }^{-}$vibrations. The peaks observed at lower than $1000 \mathrm{~cm}^{-1}$ regions can be assigned to the metal-oxygen vibrations within the layers of NiAL such as M-O-M, O$\mathrm{M}-\mathrm{O}$, and $\mathrm{M}-\mathrm{O}$ in which $\mathrm{M}$ is metal (Ni or $\mathrm{Al}$ ).

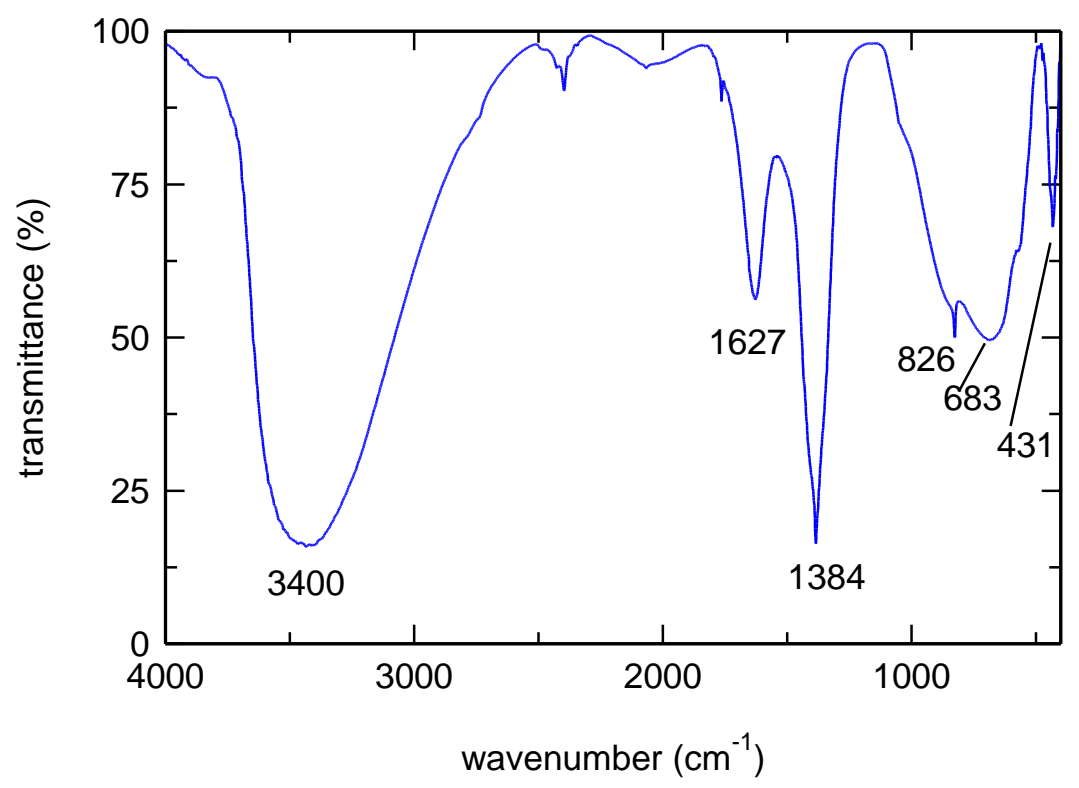

Figure 3: FTIR spectrum of NiAL

The percentage of elements present in the NiAL is as shown in Table 1. The unexpected presence of carbon in NiAL may have originated from the surrounding carbon dioxide while synthesizing the material. The presence of hydrogen and nitrogen was due to the hydroxyl group of the NiAL layers and $\mathrm{NO}_{3}{ }^{-}$ anion located in the interlayer gallery of NiAL, respectively. The presence of these elements agreed with the FTIR spectrum obtained.

Table 1 Percentage of carbon, hydrogen, nitrogen and sulphur in NiAL

\begin{tabular}{ccccc}
\hline Elements & Carbon & Hydrogen & Nitrogen & Sulphur \\
\hline Percentage $(\%)$ & 0.22 & 2.74 & 2.96 & 0 \\
\hline
\end{tabular}

The NiAL thermograms (Figure 4) indicated that the NiAL underwent two thermal decomposition steps. Firstly, it was within the temperature range of 30 to $200^{\circ} \mathrm{C}$ which was affiliated with the removal of physisorbed as well as interlayer water molecules without affecting the layered structure of the NiAL. The weight percentage of water lost from the NiAL was $24.3 \%$ (Table 2). Meanwhile, for the second thermal decomposition, the hydroxyl group in the layer and the interlayer $\mathrm{NO}_{3}$ decomposed gradually within the temperature range of 200 to $400^{\circ} \mathrm{C}$. After the hydroxyl and $\mathrm{NO}_{3}{ }^{-}$were completely decomposed, the layered structure of the $\mathrm{NiAL}$ collapsed completely causing only $50.4 \%$ of the product to remain. The product that remained is usually metal oxides. 


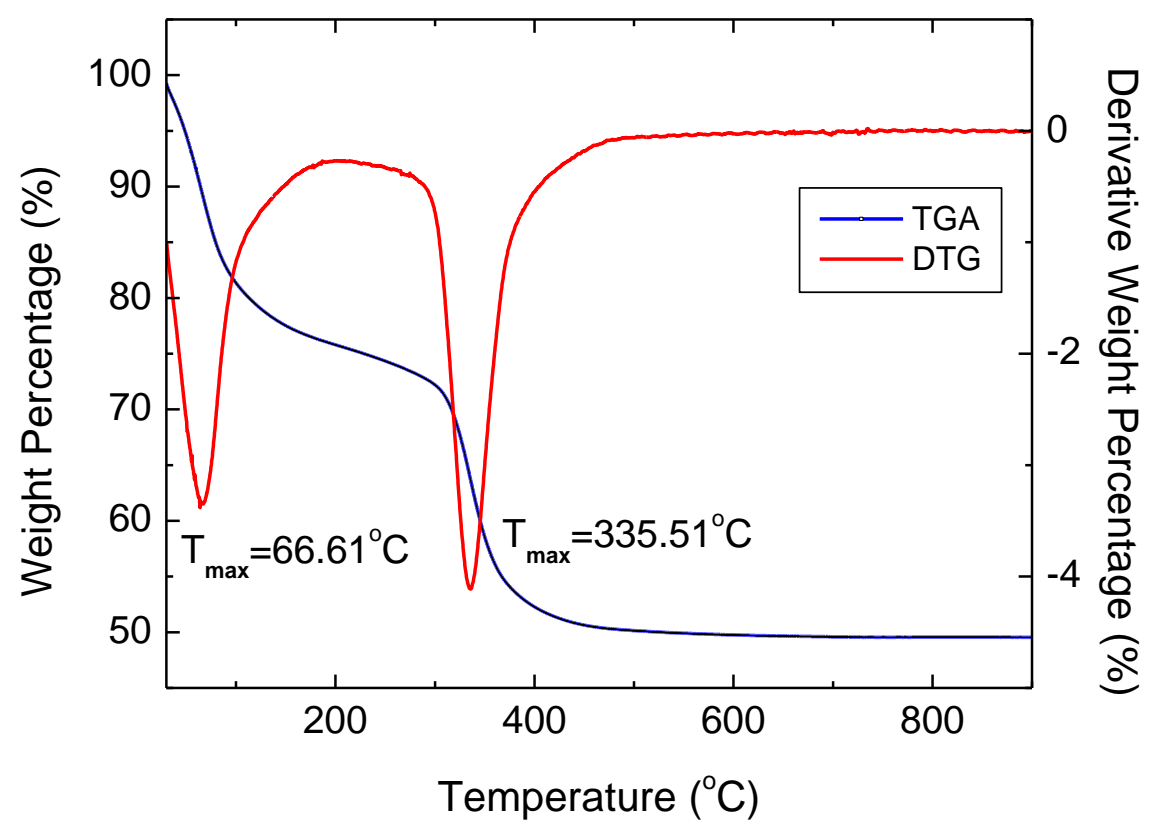

Figure 4: TGA/DTG thermograms of NiAL

Table 2 Summary of the $\mathrm{T}_{\max }$ obtained from the two decomposition steps.

\begin{tabular}{ccc}
\hline Temperature $\left({ }^{\circ} \mathrm{C}\right)$ & $\mathrm{T}_{\max }\left({ }^{\circ} \mathrm{C}\right)$ & Weight Loss $(\%)$ \\
\hline $30-200$ & 66.61 & 24.3 \\
$200-400$ & 335.51 & 25.3 \\
\hline
\end{tabular}

As for the morphological study of the NiAL, scanning electron microscope (SEM) was used. The SEM micrographs was observed under magnifications, 1000X and 5000X (Figure 5). The NiAL showed the particles agglomerate together at magnification of $1000 \mathrm{X}$. As the NiAL was viewed at higher magnification, compact, flaky and layered structure was observed.
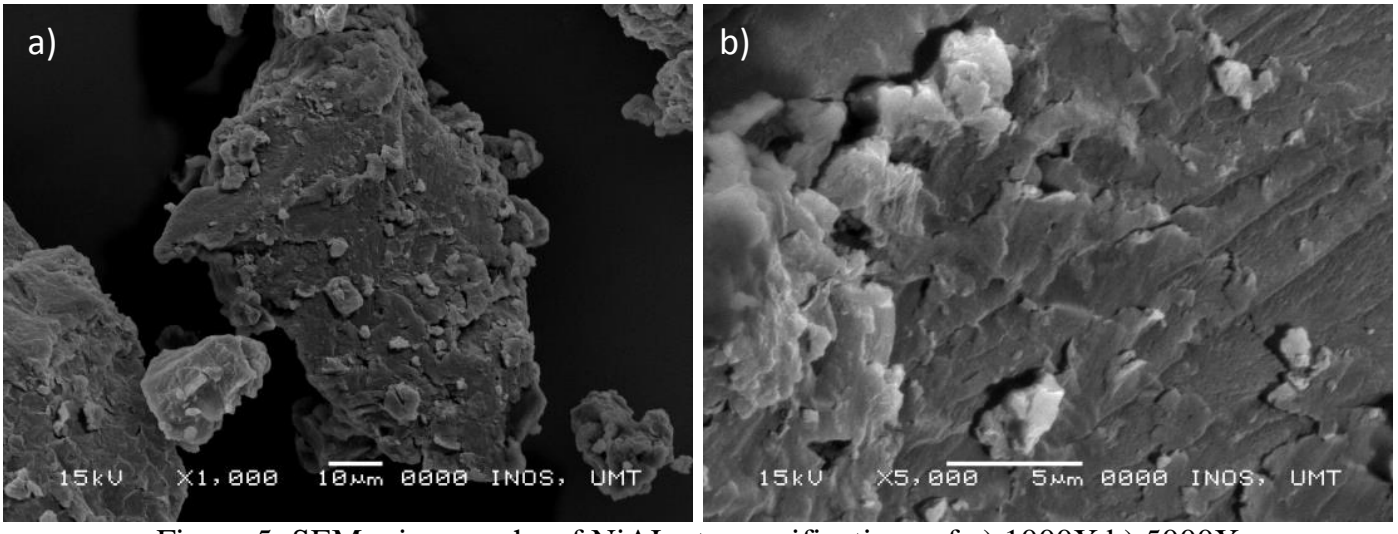

Figure 5: SEM micrographs of NiAL at magnifications of a) 1000X b) 5000X

\section{Adsorption studies}

In general, NiAL has the ability to adsorb EBT dye, a type of anionic dye. This can be seen from the percentage removal of EBT from the aqueous solution as different masses of $\mathrm{NiAL}$ put in contact with the dye (Figure 6). The adsorption of EBT seemed to have an optimum mass of $0.05 \mathrm{~g}$, where no significant change was observed beyond this mass. It is believed that this phenomenon was due to the overcrowding of the NiAL particles that 
blocked the dye molecule from accessing the binding sites on the NiAL. Hence, the graph plateaued or continued to have just slight increase if more adsorbent was added. $91.73 \%$ of the EBT dye was able to be removed from the aqueous solution when the optimum mass of NiAL was used.

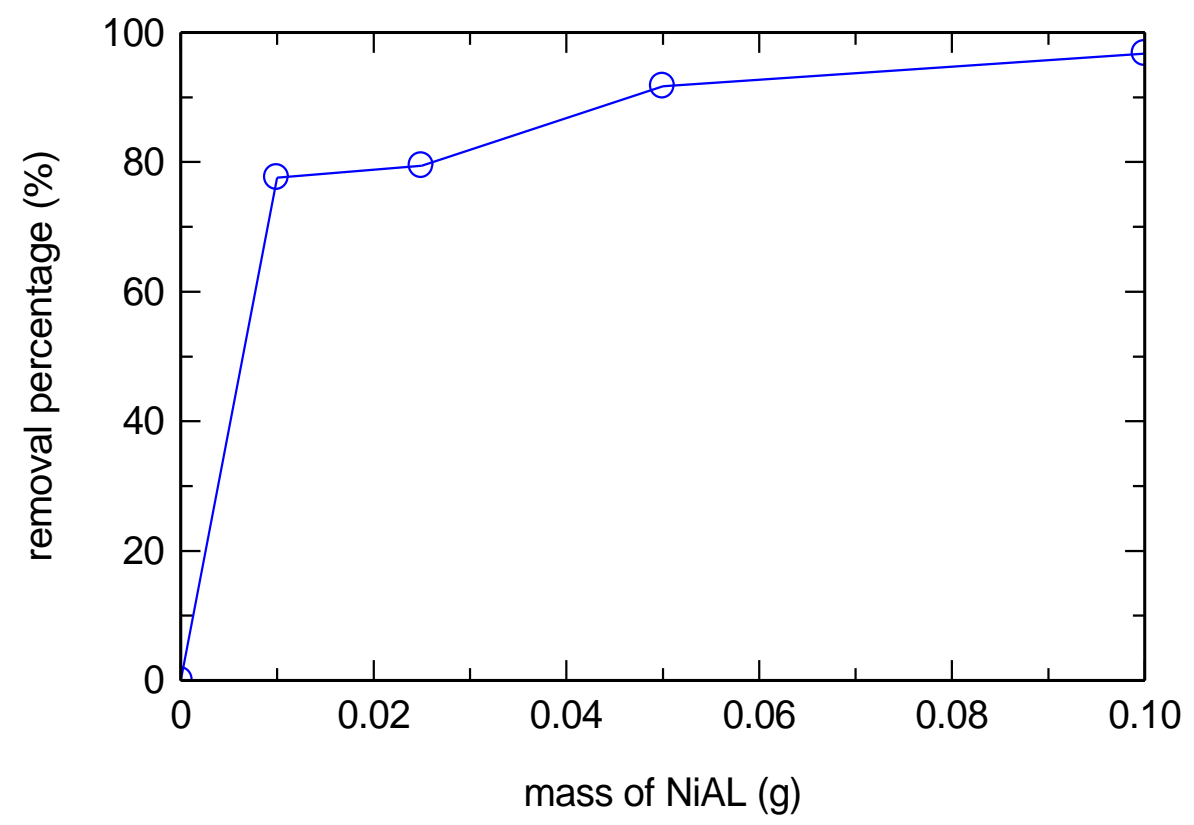

Figure 6: Removal percentage of EBT at different masses of NiAL

Two common isotherm models, namely Langmuir and Freundlich, were chosen to be tested with the adsorption data (Figure 7). The Langmuir isotherm model assumes only one molecule layer can be adsorbed onto the adsorbent surfaces (Vijayaraghavan et al., 2006). Meanwhile, Freundlich isotherm describes the multilayer adsorption, with affinities for the heterogeneous and surface non-uniform

$$
\begin{aligned}
& \frac{C_{e}}{q_{e}}=\frac{1}{q_{m} K_{L}}+\frac{C_{e}}{q_{m}} \\
& \log q_{e}=\log K_{\mathrm{F}}+(1 / n) \log C_{e}
\end{aligned}
$$

dispersal of adsorption heat (Adamson \& Gast, 1997). The linearized equations for both Langmuir and Freundlich models were used in this study to assess the best model in describing the adsorption behaviour. The equations were conveyed in equations (1) and (2), for Langmuir (Bu et al., 2016) and Freundlich (Mittal et al., 2009), respectively.

\section{Eq. 1}

Eq. 2
Where, $\mathrm{C}_{\mathrm{e}}$ is equilibrium concentration; $\mathrm{q}_{\mathrm{e}}$ and $\mathrm{q}_{\mathrm{m}}$ is the equilibrium and maximum adsorption capacity, respectively; $\mathrm{K}_{\mathrm{L}}$ is the Langmuir constant related to the free energy of the adsorption; while $\mathrm{K}_{\mathrm{F}}$ and $\mathrm{n}$ are Freundlich constants.

The value of the correlation coefficient $\left(\mathrm{R}^{2}\right)$ for the linear plot was used to determine the best model to explain the adsorption process. As for this system, the $\mathrm{R}^{2}$ value better fit the Freundlich isotherm as it gave higher $\mathrm{R}^{2}$ value (0.940) than Langmuir (0.388) which indicated that it is a type of heterogenous system and infinite amount of adsorption can occur (Allen et al., 2004). The adsorption process showed multilayer of EBT molecules adsorbed onto the NiAL binding sites which might due to the high affinity of NiAL surface towards the EBT dye. 

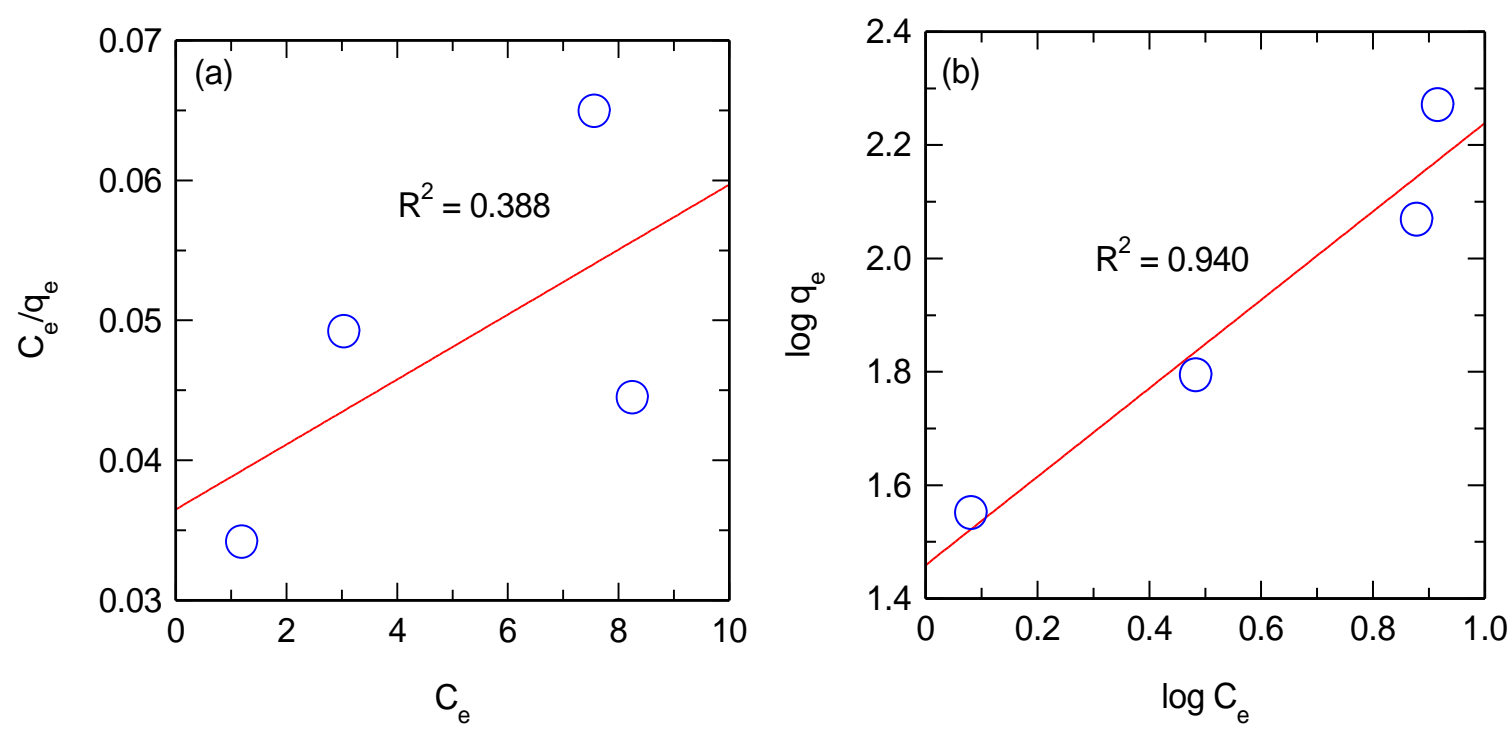

Figure 7: Fitting the data into (a) Langmuir and (b) Freundlich isotherm models

\section{Conclusion}

The NiAL with $\mathrm{NO}_{3}{ }^{-}$ion in the interlayer region was successfully synthesized via selfassembly method. The potential of synthesized $\mathrm{NiAL}$ as an adsorbent for the removal of EBT dye in aqueous solution was evaluated at different dosages of NiAL. The heterogeneous adsorption of EBT dye onto the NiAL surfaces was observed as the experimental adsorption data fitted into Freundlich isotherm model.

\section{Acknowledgements}

The authors are very grateful to Universiti Malaysia Terengganu for providing research facilities and to the Malaysian government for the funding (FRGS 59179).

\section{References}

Adamson, A.W. \& Gast A.P. (1997). Physical Chemistry of Surfaces, $6^{\text {th }}$ ed., Wiley Interscience, New York, 808 pp.

Alexandrica, M. C., Silion, M., Hritcu, D., \& Popa, M. I. (2015). Layered Double Hydroxides As Adsorbents for Anionic Dye Removal From Aqueous Solutions. Environmental Engineering and Management Journal, 14(2), 381-388.
Allen, S. J., Mckay, G., \& Porter, J. F. (2004). Adsorption isotherm models for basic dye adsorption by peat in single and binary component systems. Journal of Colloid and Interface Science, 280(2), 322-333.

$\mathrm{Bu}$, R., Chen, F., Li, J., Li, W. \& Yang, F. (2016). Adsorption capability for anionic dyes on 2-hydroxyethylammonium acetateintercalated layered double hydroxide. Colloids and Surfaces A: Physicochemical and Engineering Aspects, 511, 312 - 319.

Dave, P. N., Kaur, S., \& Khosla, E. (2011). Removal of Eriochrome black- $\mathrm{T}$ by adsorption on to eucalyptus using green technology. Indian Journal of Chemical Technology, 18, 53-60.

Goh, K. H., Lim, T. T., \& Dong, Z. (2008). Application of layered double hydroxides for removal of oxyanions: A review. Water Research, 42(6-7), 1343-1368.

Luna, M. D., Flores, E. D., Genuino, D. A., Futalan, C. M., \& Wan, M. (2013). Adsorption of Eriochrome Black T (EBT) dye using activated carbon prepared from waste rice hulls-Optimization, isotherm and kinetic studies. Journal of the Taiwan Institute of Chemical Engineers,44(4), 646653. 
Mamat, M., Tagg, T., Khairul, W. M., Abdullah, M. A. A., Mohd Tahir, N., Jubri, Z., \& As'ari, R. A. (2014). Behavior of Layered Double Hydroxides Having Different Divalent Transition Metal Groups. Applied Mechanics and Materials, 563, 94101.

Mittal, A., Kaur, D. \& Mittal, J. (2009). Batch and bulk removal of a triarylmethane dye, Fast Green FCF, from wastewater by adsorption over waste materials. Journal of Hazardous Materials, 163, 568 - 577.

Miyata, S. (1983). Anion-Exchange Properties of Hydrotalcite-Like Compounds. Clays and Clay Minerals, 31(4), 305-311.

Muriithi, G. N., Petrik, L. F., Gitari, W. M., \& Doucet, F. J. (2017). Synthesis and characterization of hydrotalcite from South African Coal fly ash. Powder Technology, 312, 299-309.

Pang, Y. L., \& Abdullah, A. Z. (2013). Current Status of Textile Industry Wastewater Management and Research Progress in Malaysia: A Review. CLEAN - Soil, Air, Water, 41(8), 751-764.

Vijayaraghavan,K., T.V.N. Padmesh, K. Palanivelu, M. Velan,. (2006). Biosorption of nickel (II) ions onto Sargassum wightii: Application of two-parameter and three parameter isotherm models. Journal of Hazardous Materials. B133, 304-308.

Yanming, S., Dongbin, L., Shifeng, L., Lihui, F., \& Shuai, C. (2017). Removal of lead from aqueous solution on glutamate intercalated layered double hydroxide. Arabian Journal of Chemistry, 10, S2295S2301.

Zubair, M., Jarrah, N., Manzar, M. S., AlHarthi, M., Daud, M., Mu'Azu, N. D., \& Haladu, S. A. (2017). Adsorption of eriochrome black $\mathrm{T}$ from aqueous phase on MgAl-, CoAl- and NiFe- calcined layered double hydroxides: Kinetic, equilibrium and thermodynamic studies. Journal of Molecular Liquids, 230, 344-352. 